\title{
Application of Liquid Chromatography-Photodiode Array Detector for Analysis of Whitening Agents in Cream Cosmetics
}

\author{
Sudibyo Martono ${ }^{1}$, Iis Febriani ${ }^{1,2}$, Abdul Rohman ${ }^{1,3^{*}}$ \\ ${ }^{1}$ Faculty of Pharmacy, Gadjah Mada University, Yogyakarta, 55281, Indonesia. \\ ${ }^{2}$ The National Agency of Drug and Food Control, Republic of Indonesia. \\ ${ }^{3}$ Research Center of Halal Products, Gadjah Mada University, Yogyakarta, 55281, Indonesia.
}

\section{ARTICLE INFO \\ Article history: \\ Received on: 07/12/2017 \\ Accepted on: 27/02/2018 \\ Available online: 30/05/2018}

\section{Key words:}

HPLC, hydroquinone, retinoic acid, cosmetics, validation.

\begin{abstract}
A study had been conducted on the optimization and validation of high-performance liquid chromatography (HPLC) method for quantitative analysis of whitening agents namely hydroquinone (HQ) and retinoic acid (RA) in cream cosmetics. Using experimental design of response surface method, the optimal condition of mobile phase resulted of methanol:water:glacial acetic acid (88:12:0.4 v/v/v), with a flow rate of $1.2 \mathrm{~mL} / \mathrm{minute}$. The separation of HQ and RA was achieved using column of STAR LP Purospher ${ }^{\circledR}$ stationary phase RP-18 end-capped $(250 \times 4.6 \mathrm{~mm}, 5 \mu \mathrm{m})$ at a temperature of $45^{\circ} \mathrm{C}$. Detection was performed using photodiode array (PDA), set at wavelength $310 \mathrm{~nm}$. HPLCPDA was validated by assessing several parameters, namely selectivity, linearity, accuracy, precision, detection limit, quantitation limit, and robustness. The validation results showed that the analytical method was selective, linear with a correlation coefficient ( $r$ ) of $\geq 0.9998$, precise with the relative standard deviation (RSD) of inter-day precision of $\leq 3.44 \%$, accurate with recovery percentage of HQ and RA of $100.00 \%$ and $99.67 \%$, respectively. The detection limits of HQ and RA were of 0.44 and $0.47 \mathrm{mg} / \mathrm{g}$, sample respectively; while the limits of quantitation of HQ and RA were of 5.09 and $1.71 \mathrm{mg} / \mathrm{g}$ samples, respectively. The developed method was successfully used for analysis of HQ and RA in commercial cream samples.
\end{abstract}

\section{INTRODUCTION}

Hydroquinone (HQ) is one of the components used as whitening agent added to cosmetics products to function as an inhibitor of melanin formation through inhibition of tyrosinase enzymes (US FDA, 2009). In medicine, HQ is used to prevent skin disorders due to hyperpigmentation such as melisma. However, if $\mathrm{HQ}$ is used extensively, it can cause hypopigmentation. HQ is also reported to have irritation and some adverse effects by destroying melanosit in human skin (Yang et al., 2010). Food and Drug Administration, Republic of Indonesia allowed the limited use of HQ in hair and nail colorants, but HQ was strictly forbidden for skin lightening cosmetics. Retinoic acid or tretinoin is vitamin A form is extensively used as anti-aging non-peeling (Kligman et

"Corresponding Author

Abdul Rohman, Faculty of Pharmacy, Gadjah Mada University,

Yogyakarta,55281, Indonesia._E-mail:abdul_kimfar@ugm.ac.id al., 1984; Darlenski et al., 2010). The chemical structures of HQ and RA were shown in Figure 1.

Analysis of HQ and RA in cosmetics samples has been reported such as normal uv-vis spectroscopy and derivative spectrophotometry for analysis of $\mathrm{HQ}$ in cream cosmetics samples (Odumosu and Ekwe, 2010; Elzanfaly et al., 2012; Kipngetich et al., 2013), visible spectroscopy based on ammonium metavanadate as an oxidizing catalyst for conversion of $\mathrm{HQ}$ to $p$-benzoquinone in the presence of oxygen (Uddin et al., 2011), ultra high performance liquid chromatography (UHPLC) using uv-vis detector (Desmedt et al., 2014), UHPLC with photo-diode array detector and UHPLC-time of flight mass spectrometer (Desmedt et al., 2013), liquid chromatography-mass spectrometer tandem mass spectrometer for analysis of RA in biological samples (Kane et al., 2005), supercritical fluid chromatography (Pfander and Niggli, 1995), high performance capillary electrophoresis (Shi et al., 1995), and isotope ratio-mass spectrometry (Parker et al., 1993). 
Most of the reported methods were intended for analysis of HQ and RA individually, while simultaneous analysis of HQ and RA was performed was carried out using LC-MS/MS which was expensive and complex. In this study, a simple HPLC using isocratic elution was validated and used for simultaneous determination of HQ and RA in cosmetics samples.

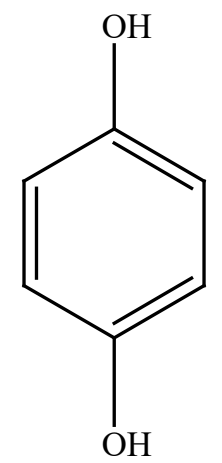

Hydroquinone

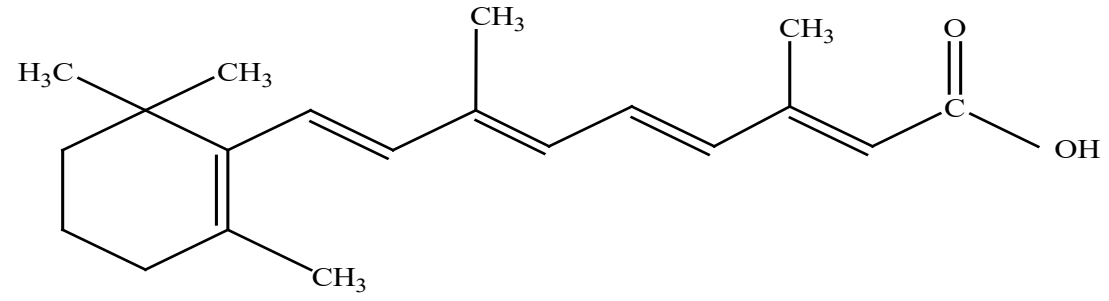

Retinoic acid

Fig. 1: The chemical structures of hydroquinone and retinoic acid.

\section{MATERIALS AND METHODS}

The reference standard of hydroquinone (HQ) and retinoic acid (RA) were obtained from Food and Drug Administration, the Republic of Indonesia. Samples of cosmetics were obtained from pharmacy around Yogyakarta, Indonesia. The solvents of mobile phase used were of HPLC grade. The solvents and reagents used were of the pro-analytical grade.

\section{Preparation of standard solution}

An approximately of $12.5 \mathrm{mg}$ of hydroquinone and 6.25 retinoic acid was accurately weighed using micro-analytical balance, added with a solvent of methanol:water:glacial acetic acid $(88: 12: 0.4 \mathrm{v} / \mathrm{v} / \mathrm{v})$ in volumetric flask $50 \mathrm{ml}$. A-3.0 mL of this solution was taken and made to $25.0 \mathrm{~mL}$ in a volumetric flask using the same solvent. The solution was filtered using membrane filter $0.45 \mu \mathrm{m}$, and $20 \mu \mathrm{L}$ solution was injected into HPLC system.

\section{HPLC measurement}

The optimum separation was performed using HPLC (Shimadzu, Japan) equipped with a photodiode-array detector (PAD) with column Purospher ${ }^{\circledR}$ STAR RP-18 end-capped (250 $\times 4.6 \mathrm{~mm}, 5 \mu \mathrm{m})$ (Merck, Germany). The composition of mobile phase, column temperature, and flow rate were optimized using response surface method. The wavelength of PDA was set at maximum wavelength scanned using UV spectrophotometer UV 1800 (Shimadzu, Japan). The injection volume was set at $20 \mu \mathrm{L}$.

\section{The Validation of the analytical method}

The validation of analytical method using optimized HPLC condition was performed according to International Conference on Harmonization (ICH, 1994) by assessing selectivity, linearity, precision, sensitivity, and robustness. The selectivity of the method was evaluated by injecting mobile phase, standard solution, and spiked samples. The linearity of hydroquinone (HQ) and retinoic acid (RA) was evaluated by preparing a standard solution containing the mixture of HQ at a concentration range of $10-60 \mu \mathrm{g} / \mathrm{mL}$ and RA at a concentration range of $5-30 \mu \mathrm{g} /$ $\mathrm{mL}$, respectively. Precision was evaluated using repeatability and intermediate precision assay. RSD value was used as acceptance criteria for precision. The accuracy of the analytical method was performed by spiked placebo using concentration levels of HQ of $20,30 \mathrm{dan} 40 \mu \mathrm{g} / \mathrm{mL}$ and RA of $10,15 \mathrm{dan} 20 \mu \mathrm{g} / \mathrm{mL}$. The recovery percentage was calculated and used for accuracy evaluation. The sensitivity of the analytical method was evaluated by the limit of detection (LoD) and limit of quantification (LoD). The robustness test was carried out by changing of oven temperature $\left( \pm 5^{\circ} \mathrm{C}\right)$ from optimum temperature and its effect on peak separation was evaluated using analysis of variance.

\section{Analysis of commercial samples}

An approximately of 0.5 -gram commercial cream cosmetics was accurately weighed in volumetric flask $25 \mathrm{~mL}$, added with $10 \mathrm{~mL}$ solvent (methanol:water:glacial acetic acid 88:12:0.4 v/v/v), mixed with a vortex mixer for 3 minutes, and made until volume using the same solvent. The solution was cooled in ice bath for 15 minutes and then filtered using membrane filter $0.45 \mu \mathrm{m}$. A-20 $\mu \mathrm{L}$ of this solution was injected in optimized HPLC system.

\section{Data analysis}

The calculation of validation data such as mean, standard deviation and RSD for evaluation of precision, the correlation coefficient for linearity and recovery percentage was calculated using Microsoft Excel 2013 (Microsoft Corp., USA). While analysis of variance (ANOVA) was carried using SPSS version 17. The response surface method was carried out using software Design Expert 7.

\section{RESULTS AND DISCUSSION}

The optimization of HPLC condition was intended to obtain optimum separation of hydroquinone and retinoic acid based on resolution, the number of theoretical plates $(\mathrm{H})$, and tailing factor (TF) with acceptable retention time. The experimental design using response surface methodology is an effective approach to find out optimum organic solvents of mobile phase (optimized at $80 \%, 85 \%$, and $90 \%$ of organic solvent), flow 
rate $(1.0,1.2$, and $1.4 \mathrm{~mL} /$ minute $)$ and column oven temperature $\left(40^{\circ} \mathrm{C}, 45^{\circ} \mathrm{C}\right.$, and $\left.50^{\circ} \mathrm{C}\right)$. The selection of HPLC condition was based on its capability to provide the optimum resolution (Rs) with acceptable retention time. Using column STAR LP Purospher ${ }^{\circledR}$ stationary phase RP-18 end-capped $(250 \times 4.6 \mathrm{~mm}, 5 \mu \mathrm{m})$, the optimum condition of mobile phase was methanol:water:glacial acetic acid $(88: 12: 0.4 \mathrm{v} / \mathrm{v} / \mathrm{v})$, with a flow rate of $1.2 \mathrm{~mL} /$ minute. The optimum oven temperature of the column was $45^{\circ} \mathrm{C}$. Detection was performed using photo-diode array (PDA) at $\lambda 310 \mathrm{~nm}$. This optimum condition offered Rs value of $\geq 2.0$, the similarity of the retention time of sample with that of standard, relative standard deviation (RSD) value of peak area and peak height $\leq 2 \%$ which meet the acceptance criteria for system suitability test (Gonzalez and Herrador, 2007). Figure 2 revealed the HPLC chromatogram of HQ and RA using an optimized condition which exhibited good separation between HQ and RA. HQ and RA were eluted at retention times of \pm 2.28 and $11.34 \mathrm{~min}$, respectively. HQ was eluted very early at $2.28 \mathrm{~min}$ which can be considered void volume for the column length $250 \mathrm{~mm}$. Therefore, blank and standards of HQ and RA were analyzed and chromatogram obtained was depicted in Figure 3. It is clear that at corresponding time retentions of HQ and RA, there was no peak in blank chromatogram proofing that peak at $\mathrm{tR} 2.28$ min was due to HQ.

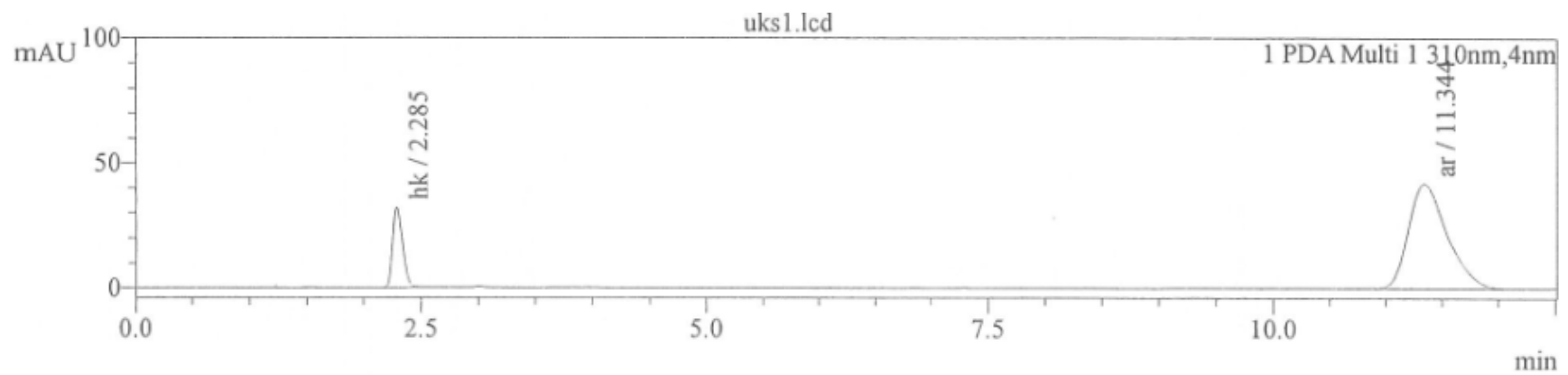

Fig. 2: The chromatogram of a standard solution of hydroquinone (HQ) at a retention time (tR) of 2.285 and retinoic acid at tR of 11.344 using optimized HPLC condition.

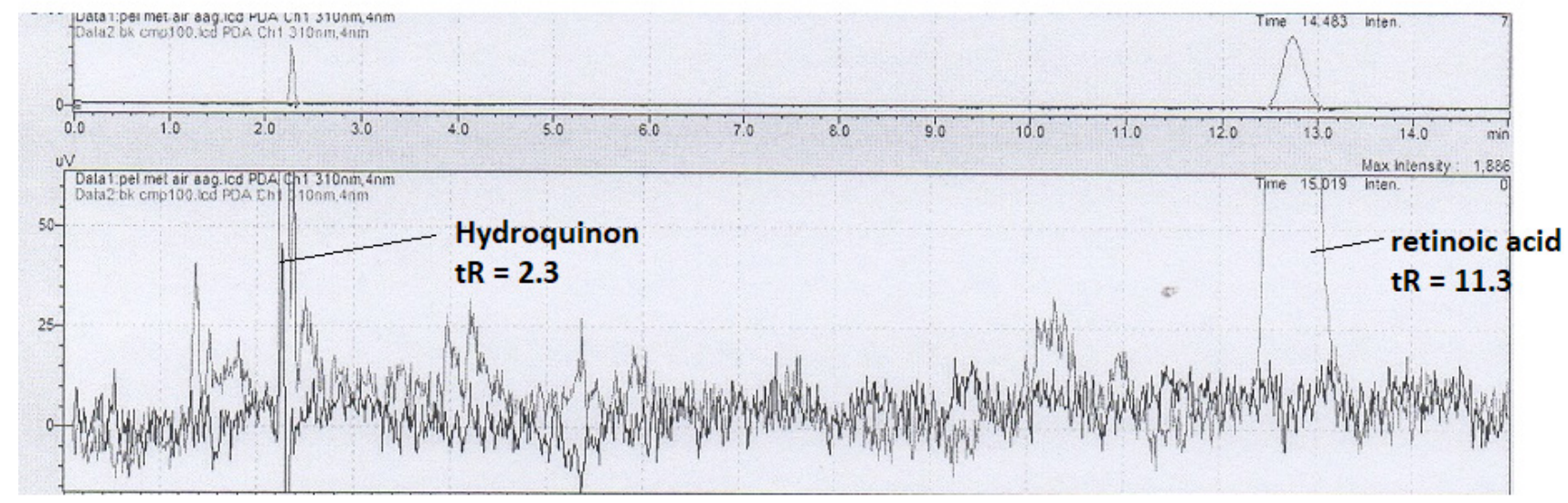

Fig. 3: The overlaid chromatogram of blank and standards of hydroquinone and retinoic acid, proofing retention time at 2.3 was due to hydroquinone.

The optimized HPLC condition was further validation to show its performance characteristics. The first validation parameter evaluated was selectivity of HPLC method to separate analytes (HQ and RA) selectively. Resolution (Rs) value was used for assessing selectivity, and Rs value of $>2.0$ was obtained, therefore the validated method was selective. For linearity evaluation, the mixture of HQ at a concentration range of $10-60 \mu \mathrm{g} / \mathrm{mL}$ and $\mathrm{RA}$ at a concentration range of $5-30 \mu \mathrm{g} / \mathrm{mL}$. The correlation coefficient (r) values obtained for HQ were 0.9998 and 0.9999 , respectively. While, \%y-intercept obtained was 0.68 and $0.025 \%$ for HQ and RA, respectively. The developed method was considered linear over concentration range because r-value $>0.999$ and \%y-intercept $<2 \%$ (Snyder et al., 2010). Figure 4 revealed the relationship between the concentration of HQ and RA along with equation of linear regression, r-value, and \%y-intercept. The sensitivity of HPLC method was expressed by the limit of detection (LoD) and limit of quantification (LoQ). The LoD and LoQ values for HQ were of 0.44 dan $5.09 \mu \mathrm{g} / \mathrm{mg}$ sample, while LoD and LOQ values for RA were 0.47 and $1.72 \mu \mathrm{g} / \mathrm{mg}$ sample, respectively.

To evaluate random and systematic errors occurring during analysis, two parameters namely precision and accuracy were evaluated. The precision of optimized HPLC condition was evaluated by repeatability (intra-day assay) and intermediate precision (inter-day assay). The RSD values were used for evaluation of precision. The method was precise if RSD values found were lower than RSD Horwitz, calculated as:

RSD Horwitz $=2^{(1-0,5 \log C)}$, in which $\mathrm{C}$ is a fraction of concentration (Gonzalez and Herrador, 2007). 

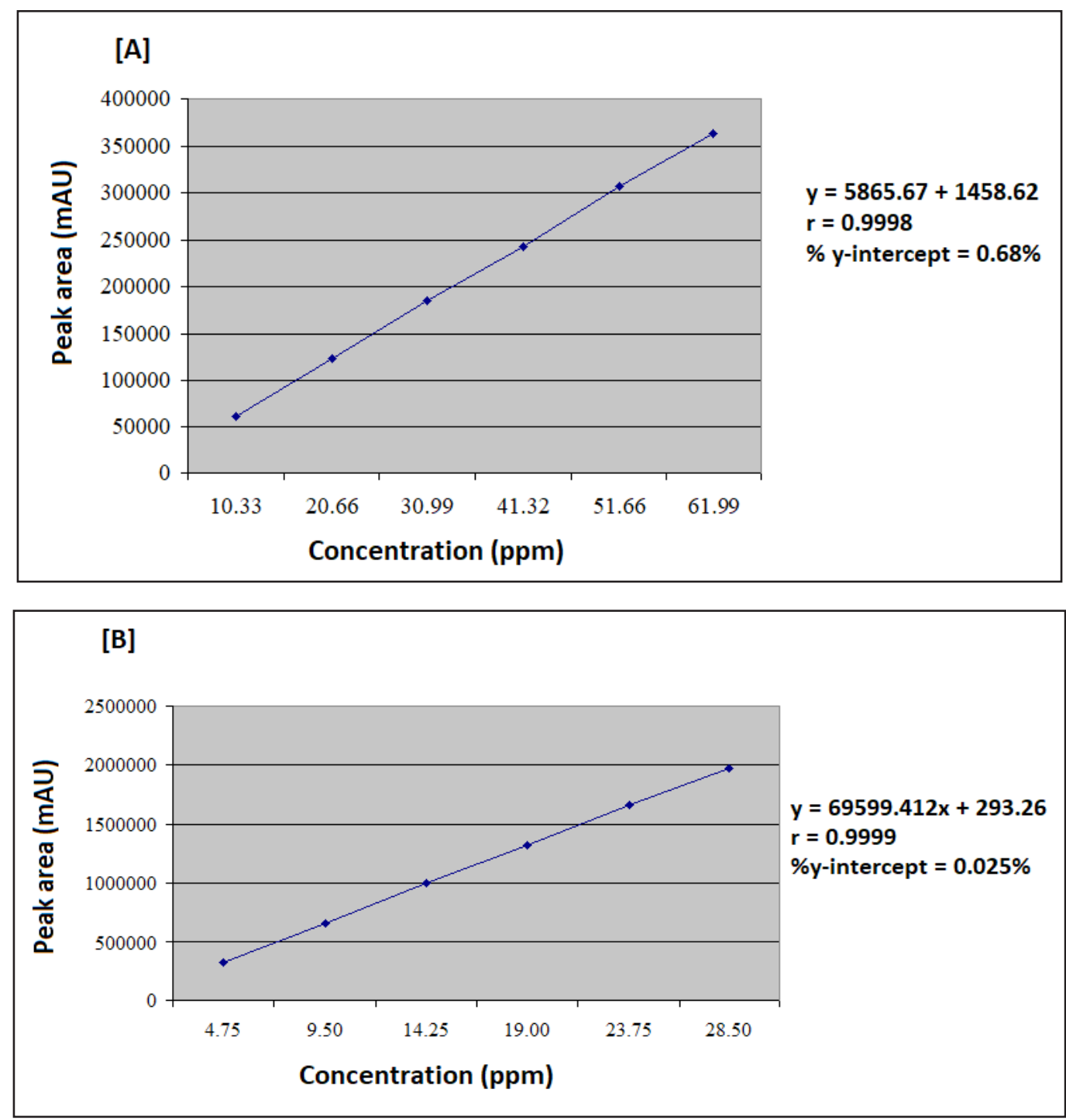

Fig. 4: The relationship between the concentration of hydroquinone $[\mathrm{A}]$ and retinoic acid $[\mathrm{B}]$ with peak area, along with equation of linear regression, r-value, and $\%$-intercept.

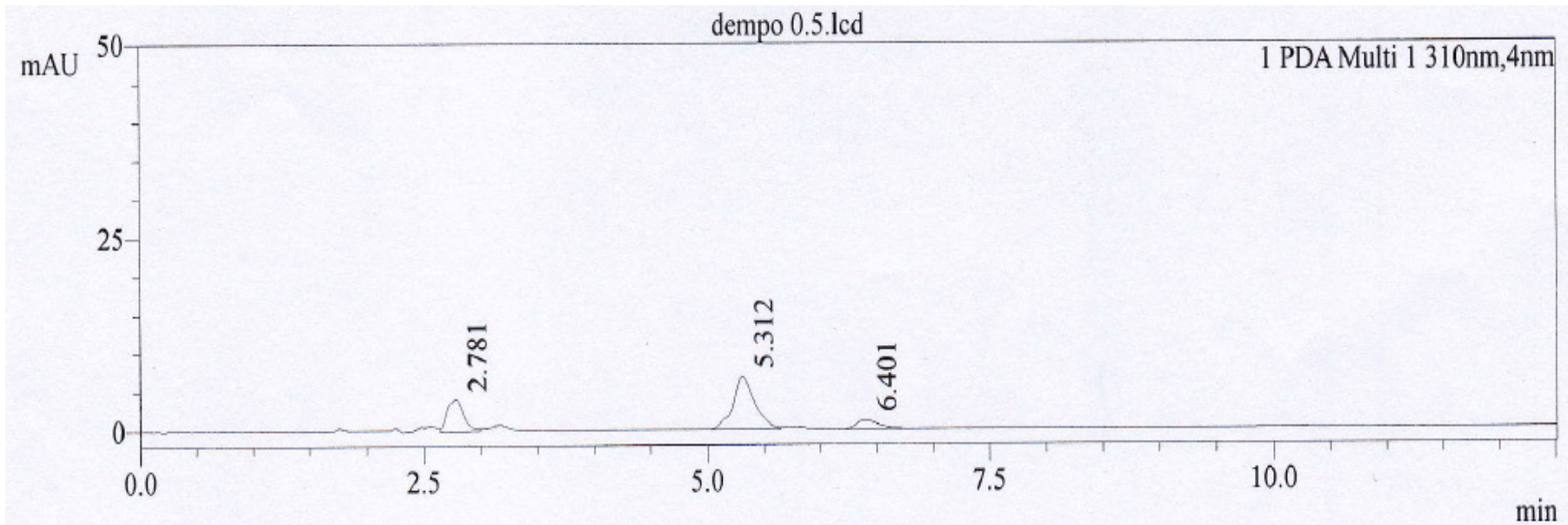

Fig. 5: The chromatogram of a sample containing hydroquinone at a retention time (tR) of 2.781 min and unknown compounds at tR of 5.312 min and 6.401 min using optimized HPLC condition. 
For precision evaluation of $\mathrm{HQ}$, the RSD values for intraday during three-week measurement were $0.58 \%, 0.33 \%$, and $0.59 \%$, respectively, while RSD value for inter-day was $3.44 \%$. While RSD values for intra-day of RA were $1.98 \%, 0.84 \%$, and $0.60 \%$, respectively with RSD value of inter-day was $1.34 \%$. All these RSD values were lower than required RSD Horwitz $( \pm 10 \%)$.

The accuracy of the analytical method was evaluated by spiked placebo and the recovery percentage was used as accuracy indication. The average of \% recovery obtained was $100 \%$ for HQ and $99.67 \%$ for RA. The required \% recovery for the level of analytes $1 \mathrm{ppm}$ is $80-110 \%$, therefore the validated HPLC method was accurate. The robustness was carried out by changing oven temperature from optimum temperature $\left(45^{\circ} \mathrm{C}\right)$ into $\pm 5^{\circ} \mathrm{C}$, namely $40^{\circ} \mathrm{C}, 45^{\circ} \mathrm{C}$, and $50^{\circ} \mathrm{C}$. The results, based on ANOVA test followed by independent t-test, indicated that temperature change over specified value did not affect significantly $(\mathrm{P}>0.05)$. Based on validation results, it can be concluded that HPLC at optimized condition was valid for analysis of HQ and RA in real samples. Figure 5 revealed HPLC chromatogram of a commercial sample containing hydroquinone and unknown compounds. It is known that validated HPLC can analyze HQ selectively from other components in commercial samples.

\section{CONCLUSION}

Reversed-phase HPLC using optimized mobile phase consisted methanol:water:glacial acetic acid (88:12:0.4 v/v/v) in an isocratic manner with a flow rate of $1.2 \mathrm{~mL} /$ minute was successfully used for analysis of hydroquinone and retinoic acid in cream cosmetics. The developed method is relatively fast and does not involve extensive sample preparation.

\section{ACKNOWLEDGMENT}

The authors would like to thank the Food and Drug Agency, District Palu, Central Sulawesi for instrument facilities during this research.

\section{REFERENCES}

Darlenski R, Surber C, Fluhr JW. Topical retinoids in the management of photodamaged skin: from theory to evidence-based practical approach. Br. J. Dermatol. 2010; 163:1157-1165.

Desmedt B, Rogiers V, Courselle P, De Beer JO, De Paepe $\mathrm{K}$, Deconinck E. Development and validation of a fast chromatographic method for screening and quantification of legal and illegal skin whitening agents. J. Pharm. Biomed. Anal. 2013; 83:82-88.

Desmedt B, Van Hoeck E, Rogiers V, Courselle P, De Beer JO, De Paepe K, Deconinck E. Characterization of suspected illegal skin whitening cosmetics. J. Pharm. Biomed. Anal. 2014; 90:85-91.

Elzanfaly ES, Saad AS, Abd-Elaleem AEB. Simultaneous determination of retinoic acid and hydroquinone in skin ointment using spectrophotometric technique (ratio difference method). Saudi Pharm. J. 2012; 20:249-253.

Gonzalez AG, Herrador MA. A Practical Guide to Analytical Method Validation, Including Measurement Uncertainty and Accuracy Profiles. Trends Anal. Chem. 2007; 26:227-238.

International Conference on Harmonization/ICH Q2(R1). Validation of Analytical Procedures: Text and Methodology. ICH Harmonized Tripartite Guideline, 1994; 2(1):6-13.

Kane MA, Chen N, Sparks S, Napoli JN. Quantification of endogenous retinoic acid in limited biological samples by LC/MS/MS. Biochem. J. 2005; 388:363-369.

Kipngetich TE, Hillary M, Shadrack M. UV-VIS analysis and determination of hydroquinone in body lotions and creams sold in retail outlets in Baraton, Kenya. Baraton Interdis. Res. J. 2013; 3(1):23-28.

Kligman LH, Chen HD, Kligman AM. Topical retinoic acid enhances the repair of ultraviolet damaged dermal connective tissue. Connect Tissue Res. 1984; 12:139-50.

Odumosu PO, Ekwe TO. Identification and spectrophotometric determination of hydroquinone levels in some cosmetic creams. Afr. J. Pharm. Pharmacol. 2010; 4(5):231-234.

Parker RS, Swanson JE, Marmor B, Goodman KJ, Spielman AB, Brenna JT, Viereck SM, Canfield WK. Study of beta-carotene metabolism in humans using ${ }^{13} \mathrm{C}$-beta-carotene and high precision isotope ratio mass spectrometry. Ann. N.Y. Acad. Sci. 1993; 691:86-95.

Pfander H, Niggli U. Chromatography: Part V. Supercritical-fluid chromatography. Britton G. Liaaen-Jensen S. Pfander H. eds. Carotenoids. 1A Isolation and Analysis. 1995; pp.191-198.

Shi H, Ma Y, Humphrey JH, Craft NE. Determination of vitamin A in dried human blood spots by high-performance capillary electrophoresis with laser-excited fluorescence detection. J. Chromatogr. B. Biomed. Appl. 1995; 665:89-96.

Snyder LR, Kirkland JJ, Dolan JW. Introduction to Modern Liquid Chromatography, third edition, USA: John Wiley \& Sons Inc. Publication, New York, 2010; pp 543.

Uddin S, Rauf A, Kazi TG, Afridi HI, Lutfullah G. Highly sensitive spectrometric method for determination of hydroquinone in skin lightening creams: application in cosmetics. Int. J. Cosmet. Sci. 2011; 33(2):132-7.

U.S Food \& Drug Administration Department of Health and Human Service. Hydroquinone (CAS 123-31-9), Supporting Information for Toxicological Evaluation by the National Toxicology Program, Austin, 2009. pp 4-40.

Yang CH, Chen YS, Lai JS, Hong WWL, Lin CC. Determination of the Thermodegradation of deoxyArbutin in Aqueous Solution by High Performance Liquid Chromatography, Int. J. Mol. Sciences. 2010; 11:39773987.

How to cite this article:

Martono S, Febriani I, Abdul Rohman. Application of liquid chromatography-photodiode array detector for analysis of whitening agents in cream cosmetics. J App Pharm Sci, 2018; 8(05): 143-147. 